\title{
Laboreal
}

Volume 15 N$^{\circ} 2$ | 2019

Varia

\section{O trabalho de supervisão em uma indústria de pneumáticos : entre o trabalho real e o discurso oficial do gerenciamento}

El trabajo de supervisión en una industria de neumáticos : entre el trabajo real y

el discurso de los profesionales de la gestión

Le travail de supervision dans une industrie du pneu : entre le travail réel et le

discours des professionnels de la gestion

The supervision work in a tire industry: between the actual work and the

managers official speech

Cirlene de Souza Christo, Marcello Santos Rezende e Milton Athayde

\section{OpenEdition}

Journals

Edição electrónica

URL: http://journals.openedition.org/laboreal/15047

DOI: $10.4000 /$ laboreal. 15047

ISSN: 1646-5237

Editora

Universidade do Porto

Refêrencia eletrónica

Cirlene de Souza Christo, Marcello Santos Rezende e Milton Athayde, «O trabalho de supervisão em uma indústria de pneumáticos : entre o trabalho real e o discurso oficial do gerenciamento », Laboreal [Online], Volume 15 №2 | 2019, posto online no dia 01 dezembro 2019, consultado o 11 abril 2020. URL : http://journals.openedition.org/laboreal/15047 ; DOI : https://doi.org/10.4000/laboreal.15047

Este documento foi criado de forma automática no dia 11 abril 2020.

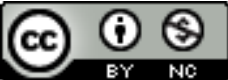

Laboreal está licenciado com uma Licença Creative Commons - Atribuição-NãoComercial 4.0 Internacional. 


\title{
O trabalho de supervisão em uma indústria de pneumáticos : entre o trabalho real e o discurso oficial do gerenciamento
}

\author{
El trabajo de supervisión en una industria de neumáticos : entre el trabajo real y \\ el discurso de los profesionales de la gestión \\ Le travail de supervision dans une industrie du pneu : entre le travail réel et le \\ discours des professionnels de la gestion \\ The supervision work in a tire industry: between the actual work and the \\ managers official speech
}

Cirlene de Souza Christo, Marcello Santos Rezende e Milton Athayde

\section{NOTA DO EDITOR}

Manuscrito recibido en : julio 2018

Aceptado tras peritage : octubre 2019

\section{Introdução}

1 A problemática que se propõe discutir nesse texto envolve as reconfigurações no trabalho de supervisão de produção industrial[1] em contexto de inovações tecnológicas e organizacionais. Mudanças impulsionadas pelo que se tem denominado "reestruturação produtiva", incluindo informatização de base microeletrônica, reestruturação de linhas de produção, diminuição de níveis hierárquicos, descentralização do gerenciamento e abordagens de controle de qualidade. É frequente na literatura a indicação de alterações no trabalho de gerentes de nível médio, ou 
chefes de equipes de produção, em termos de reformulações de suas tarefas de comando, de acompanhamento e de coordenação do pessoal (Bellini \& Labit, 2005). Para além das tradicionais tarefas de comando e controle do trabalho dos integrantes das equipes de produção segundo os critérios definidos pela organização empresarial, tendencialmente, o escopo desse tipo de trabalho estar-se-ia ampliando no sentido de incluir exigências de aproximação com os serviços de apoio e direção da empresa. Renovam-se as tarefas de comando, de acompanhamento e de coordenação do pessoal e somam-se a elas propostas de recomposição do trabalho dos operadores com alargamento de suas responsabilidades na gestão da produção (Trouvé, 2009; Mispelblom-Beyer \& Bismuth, 2009), requerendo também maior disponibilidade para os operadores, com vistas à formação e incentivo à participação. Uma das mudanças verificadas é a supressão de alguns níveis hierárquicos de chefia, com criação implícita ou explícita de novos cargos de supervisão em níveis hierárquicos superiores. Bouffartigue e Bouteiller (2004) argumentam que, com a transição das atividades de comando anteriormente mais ligadas à sanção dos desvios às prescrições para a proposição de uma ênfase na coordenação das equipes de trabalho, cada vez mais se requer desses profissionais capacidades relacionais e qualidades de facilitação das relações humanas.

2 Essas mudanças têm sido objeto de pesquisas empíricas também no Brasil. Em levantamento bibliográfico realizado nas bases de dados que compõem o Portal Periódicos da Coordenação de Aperfeiçoamento de Pessoal de Nível Superior (CAPES), do Ministério da Educação e Cultura (MEC) do Brasil, identificaram-se, entre 2007 e $2017\left[^{2}\right], 39$ artigos sobre o trabalho de supervisão. Deles, $10 \%$ dedicavam-se ao estudo das relações hierárquicas, autonomia, idade e percepção de poder entre supervisores e empregados ; 13 \% à investigação sobre as causas e efeitos de relação de supervisão abusiva nas atitudes e comportamento organizacional, assim como na exaustão emocional dos empregados; ; $15 \%$ à pesquisa sobre as implicações do trabalho destes profissionais no processo saúde-doença dos trabalhadores sob sua supervisão. Entretanto, a maior parte das pesquisas (62\%) orientou-se para o estudo do que denominaram atitudes, habilidades de comunicação, construção de valores, relações de confiança, escuta e suporte social. Isto é, para o estudo da dimensão relacional do trabalho de supervisão, assim como para suas implicações no comportamento e desempenho dos trabalhadores, na satisfação destes com o trabalho, na retenção da força de trabalho, no comprometimento organizacional, na transferência de aprendizagem dos treinamentos, no fomento da justiça social, assim como nas percepções e comportamento político dos trabalhadores.

3 No que se refere à produção das ciências da gestão, pode-se dizer que os princípios da “Teoria Geral da Administração" tal como desenvolvidos por Fayol (1968/1916) continuam a influenciar os principais estudos sobre o trabalho gerencial, fazendo com que sejam preponderantes na literatura orientações normativas e indicações sobre o que se espera do gerente em termos de comportamentos e atitudes, em detrimento das que se propõem à descrição e à compreensão de suas atividades. As pesquisas, desenvolvidas principalmente com base na literatura anglo-saxã, privilegiam a abordagem deste trabalho tanto sob a perspectiva de seu processo quanto a de definição das responsabilidades e papéis dos gerentes, destacando-se a de transmitir e fomentar junto ao nível operacional o alcance dos objetivos organizacionais. 
4 Identificam-se também esforços no sentido de discutir o trabalho gerencial para além dessa perspectiva normativa. Ao contrário de ser previsível e planejado, o trabalho gerencial comporia como um conjunto complexo de atividades que requerem mais do que habilidades e conhecimentos uniformes. Especificamente em relação ao trabalho de supervisão, alguns autores (Faverge, 1966 ; Dejours \& Jayet, 1994 ; Faïta \& Duc, 1996 ; Rogard \& Béguin, 1997 ; Carballeda \& Garrigou, 2001 ; Mascia, 2007) apontam para um denominador comum : o direcionamento real e não somente prescrito do trabalho dos que estão sob sua responsabilidade. Essas pesquisas indicam que, assim como outros, o conteúdo do trabalho de supervisão não pode ser totalmente definido a priori, mas construído com a situação. Tanto quanto ou mais do que outros trabalhadores, os supervisores lidam com a variabilidade da produção na interação das dimensões técnica, humana e social, assim como as diferentes racionalidades provenientes de diferentes serviços que compõem o sistema organizacional, fazendo a interface entre o ambiente - muitas vezes constrangedor e flutuante - e a organização do trabalho. Segundo Mascia (2007), sua tarefa se desenvolve em um processo de integração e dissociação de elementos múltiplos e heterogêneos, que envolve tornar compatíveis as condições internas do nível operacional e as exigências dos outros subsistemas. Mas, a despeito de tais estudos, mesmo no campo da Ergonomia da Atividade, poucos ainda são os estudos que abordam a distinção entre as tarefas e as atividades realizadas por estes profissionais (Falcoz \& Livian, 2006). Tal escassez, em comparação aos estudos ergonômicos relativos à atividade de operários nas indústrias, faz com que o conhecimento sobre esse trabalho esteja muito aquém da sua importância na implantação e efetividade das formas de organização do trabalho atuais em termos de produtividade \& qualidade, saúde \& segurança.

5 De outro modo, a análise pode se beneficiar ao incorporar o debate sobre a emergência de uma ideologia gerencialista nas sociedades contemporâneas (Gaulejac, 2007) que em muito dizem respeito ao trabalho gerencial. Nesse debate analisa-se o quão fortemente pode ser vivida a contradição capital / trabalho pelos profissionais que ocupam funções gerenciais. Isto por localizarem-se no centro da tensão entre as exigências de adaptação às expectativas do mercado e a necessidade de melhoria das condições de trabalho e de vida dos trabalhadores e de si próprios. Ao mesmo tempo em que têm seu trabalho enquadrado pela exigência de identificação com os interesses da empresa, encontramse em uma condição social submetida a uma lógica de concorrência e pressão que expõem eles próprios ao risco de dispensa. $\mathrm{E}$ isso não pode ser desconsiderado na busca de compreensão das gestões cotidianas em suas atividades de trabalho. Dejours (1999) adverte que as novas formas de dominação e manipulação gerencial - especialmente a ameaça de precarização do emprego - gerariam um medo constante nos gerentes, fazendo com que tendessem a adotar comportamentos de obediência e submissão e adesão ao discurso oficial do gerenciamento, mesmo tendo consciência de suas contradições e incoerências diante das situações reais de trabalho. Chama-se, portanto, a atenção para um ponto de vista presente nessa discussão : não o do gerente enquanto apenas vítima deste sistema, mas como o de quem consente e participa de sua manutenção.

6 Cada vez mais as organizações solicitam aos trabalhadores (incluindo os gerentes) a agir, decidir, participar e tomar iniciativas. $\mathrm{E}$ o fazem tomando, prioritariamente, os valores de mercado como referência na produção de normas antecedentes, conferindo a elas um significativo uso como instrumentos de exploração econômica e dominação 
social, jurídico-política (Schwartz, 2005), Mas, justamente porque nenhuma norma é puramente técnica e - por isso mesmo - neutra (Schwartz, 2011), pode-se supor a não submissão total das pessoas aos imperativos de normas antecedentes fundadas exclusivamente em valores mercadológicos.

7 Schwartz (2007) afirma que além de "impossível", como demonstrada pelos ergonomistas, a total antecipação da atividade humana é também "invivível", insuportável de viver. Ele baseia essa proposição no pensamento do filósofo (e médico) francês Canguilhem $(2001 / 1947 ; 2010 / 1966)$, para quem a saúde é proveniente de um debate (uma luta ou embate) sempre renovado entre normas anônimas provindas do meio e normas que cada ser produz no confronto com o meio natural e social. Por este ponto de vista, ser sujeito de suas normas é condição fundamental para a vida do homem. Segundo Schwartz (2005), devido às infidelidades do meio e à singularidade das pessoas e das situações de trabalho, a atividade representa uma dinâmica de contradições potenciais, colocando-se sempre como um lugar de debates entre normas antecedentes e tendências a renormatizações. Estas renormatizações, resultado das microescolhas realizadas no curso das atividades de trabalho, podem até mesmo estar produzindo novas técnicas e saberes que, quiçá, serão incorporados/patrimonializados às normas antecedentes. Elas representam a potência humana de exercer o vai-e-vem entre a ordem do estabelecido, a norma, e a tendência ao agir em aderência no aqui e agora, tornando-se necessário gerir o que não foi previamente normalizado (Schwartz \& Durrive, 2009). E como este gerir se faz por intermédio de cada pessoa, de cada protagonista do trabalho, de vidas singulares, cada ser humano introduziria permanentemente algo de si na situação.

8 Assim, em se tratando de profissionais que normalmente provêm e se mantêm vinculados ao lugar (operação) onde se defrontam diferentes racionalidades nem sempre convergentes, e em um lugar onde se vivenciam diretamente as contradições econômicas e sociais do processo produtivo, colocam-se algumas questões : o trabalho de supervisão se resumiria a uma transmissão e controle da execução das prescrições do gerenciamento ou a uma tradução prática das políticas da empresa? Suas competências se restringiriam ao convencimento e à argumentação com fins de aplicação das orientações e referenciais por ela adotados? No curso da ação, que normas entram em embate, que valores são convocados e que reservas de alternativas (Schwartz \& Durrive, 2010) emergem em suas atividades de trabalho?

9 Reiterando a pertinência de se mobilizar o conceito de atividade (Athayde \& Rezende, 2015 ; Schwartz, 2007) procedeu-se em uma pesquisa-intervenção (Christo, 2013) à análise do trabalho de supervisores de equipes de produção, cujo objetivo foi compreender como eles fazem a gestão da interface entre as diretrizes e objetivos estratégicos da empresa e as múltiplas exigências que se apresentam nas situações concretas de trabalho, buscando destacar as implicações subjetivas e intersubjetivas da realização desse trabalho.

\section{Método de pesquisa}

A pesquisa foi realizada em uma unidade industrial de uma empresa multinacional de fabricação e comercialização de produtos pneumáticos instalada no Brasil[ $\left.{ }^{3}\right]$. A escolha da unidade industrial como campo empírico de investigação se deu por estar em curso a implantação de um projeto de mudança da organização do trabalho, envolvendo 
redução dos níveis hierárquicos, adoção de estrutura matricial de responsabilidades, com projeto de responsabilização (PR) dos operadores de produção por tarefas que antes eram das chefias. Esse projeto se sustentava com base em um novo sistema de tecnologia de informações gerenciais. As mudanças propostas pressionavam em direção a uma reconfiguração das tarefas dos Supervisores de Equipes (SE, cargo novo na empresa, criado com a eliminação do de chefe de setor e a responsabilização dos operadores por tarefas que antes eram dos chefes). Nessa fábrica, as equipes de produção eram organizadas em turnos de oito horas, o que permitia seu funcionamento 24 horas por dia. Cada unidade de produção pela qual os SE se tornaram responsáveis era composta por em média três setores, contando cada um com quatro equipes de produção que trabalhavam em três turnos, tendo sempre uma equipe em folga.

11 A identificação da possibilidade de análise das questões levantadas na pesquisa se deu pela aproximação da primeira autora ao campo, onde atuava como consultora, levando a um pedido à direção da empresa de autorização para uma análise do trabalho dos SE nesse contexto de mudanças organizacionais e tecnológicas. A autorização foi dada em função do entendimento do RH e da direção da fábrica de que as ações da pesquisa poderiam contribuir também para os objetivos do projeto AR no que se referia à formação dos SE, via participação deles no processo de análise de seu trabalho. Ao longo da pesquisa os objetivos, focos, métodos e meios da análise do trabalho foram discutidos individual e coletivamente com os membros da direção e os SE, estabelecendo-se o acordo de que, a despeito das ações serem realizadas na fábrica e no horário de expediente, a participação seria voluntária. Uma estratégia adotada foi a de não reporte à direção da empresa de informações sobre presença e participação dos $\mathrm{SE}$ nas atividades de pesquisa.

12 A estratégia metodológica da pesquisa orientou-se para a construção de um dispositivo que em Ergologia denomina-se "Encontros sobre o Trabalho" - EsT (Durrive, 2010; Athayde, Muniz, França \& Figueiredo, 2010 ; Athayde, Zambroni-de-Souza \& Brito, 2014). Tal dispositivo viabiliza o funcionamento de um espaço de diálogo-debate sobre o trabalho dos SE, em um exercício de confrontação de dois registros: o das normas antecedentes (incluindo as tarefas prescritas) e o das atividades de trabalho. Tendo como base o princípio da autoconfrontação (Pinsky \& Theureau, 1982 ; Clot \& Leplat, 2005 ; Faïta \& Maggi, 2007), privilegiou-se um enquadramento clínico (Bendassolli \& Soboll, 2014 ; Lhuilier, 2006) da pesquisa. O objetivo era favorecer - por meio da troca verbal dos supervisores sobre o objeto de seu próprio trabalho com os colegas e com os pesquisadores - a deflagração de um novo contexto : um (re)encontro entre os SE e suas atividades de trabalho, ao engendrar uma atividade de pensamento e linguagem sobre elas, tendo quiçá o potencial (individual e coletivo) de produzir novos possíveis para suas atividades de trabalho (Faïta \& Maggi, 2007).

Os EsT foram precedidos por uma etapa de análise global do trabalho (Guérin et al, 2001), em que a demanda dos pesquisadores pôde ser discutida com a direção e SE, no sentido de sua análise e reformulação. Essa etapa foi iniciada por entrevistas realizadas individualmente com o diretor da fábrica, quatro gerentes, dois membros dos serviços de apoio e três SE direcionadas à análise global e do trabalho dos SE. Nelas se buscou conhecer o funcionamento geral da empresa e as normas antecedentes do trabalho realizado pelos SE, assim como debater sobre os objetivos caminhos da intervenção. A forma como encaminhamos a entrevista, ou como a ela chegamos, tem a ver com o que apontaram Rocha, Daher e Sant'Anna (2004). No lugar de toma-la como ferramenta para 
a imediata captação e apropriação da informação desejada e de incorporar o entrevistado como mero informante que teria uma informação com valor de verdade, entendemos ser necessário, no diálogo com os trabalhadores - gerando estranhamentos e controvérsias - explorar as consequências da natureza polifônica da linguagem, assim como colaborar para que eles assumam o lugar de sujeito de análise, tomando para si a tarefa de interpretar o trabalho em análise, desenvolvendo-se.

Concomitantemente, procedeu-se ao levantamento de documentos sobre o processo de produção; os métodos de gerenciamento; a história ; o mercado em que a empresa estava inserida; os regulamentos e as políticas organizacionais. Foram realizadas observações livres do trabalho em três setores de produção aproveitando para eventuais conversas com os SE sobre seu trabalho e sobre a demanda. relatórios descritivos. Foi feita uma análise e discussão desses materiais pelo coletivo de pesquisadores que estiveram à frente da investigação[ $\left.{ }^{4}\right]$. Elas foram orientadas para a identificação de elementos que pudessem indicar possíveis conflitos entre as normas antecedentes e entre elas e as situações reais de trabalho até então descritas ou observadas, que pudessem servir como elementos disparadores da discussão nos EsT. Esses elementos foram organizados por temas e apresentados aos SE, propondo uma discussão sobre estes e outros possíveis temas a serem abordados nos EsT. Foram definidos como temas para os EsT: delegação de tarefas; autonomia e responsabilização dos operadores; hierarquia e construção da cooperação; comunicação e construção de sentido; e prescrição do gerenciamento. Cada participante tinha a tarefa se preparar para o encontro, registrando dados de situações concretas a serem objeto de discussão no encontro.

16 A formação se deu por meio da realização de EsT, que foram desenvolvidos da seguinte forma : apresentação de materiais conceituais do campo da Ergonomia da Atividade e da démarche ergológica (20 minutos em média) pertinentes aos temas selecionados pelos pesquisadores[5] e os SE no primeiro Encontro, seguidas de diálogos-debates mobilizados pela confrontação com trechos de diálogos sobre o trabalho estabelecidos na fase preliminar da pesquisa e nos Encontros anteriores (1h10 em média). Esses textos (produzidos em outros contextos) alimentavam os diálogos sobre o trabalho, reconstruindo-se em cada Encontro e em cada reunião da equipe de pesquisadores profissionais destinados à sua preparação[ $\left.{ }^{6}\right]$.

17 A partir da análise da distância entre os registros das atividades e o das prescrições e normas antecendentes, buscou-se realizar com os SE um debate crítico, tanto acerca das condições em que seu trabalho se realizava, quanto das mobilizações subjetivas que ele implicava. Um trabalho de co-elaboração crítica que envolve riscos.

18 Segundo Schwartz (2010), o primeiro risco é o de se dispor a colocar em análise suas escolhas (nem sempre conscientes) nos debates de normas das atividades, assim como os critérios (que envolvem diferentes valores) utilizados nessa escolha. Expressar as escolhas e possíveis renormatizações (ou seja, o potencial do ser vivo para gerar novas normas, mais pertinentes a si) envolve também risco político numa situação profissional regulada-regulamentada por relações hierárquicas e subordinação jurídica. Primeiro buscou-se alertar os participantes sobre tais riscos em uma reunião de apresentação/discussão sobre procedimentos da pesquisa e, em seguida, construir um contrato psicossocial (Rousseau \& Parks, 1993) de respeito à decisão de cada um quanto a participar ou não de qualquer etapa. Acordou-se que, apesar da direção da fábrica 
sugerir que todos participassem da pesquisa (que entendia contribuir para a formação dos supervisores), não haveria qualquer reporte à mesma sobre a participação ou não dos supervisores em qualquer de suas etapas.

Realizaram-se cinco EsT com a participação de onze SE[7]ao total, gravados em áudio, todos ocorrendo no espaço da própria fábrica, no início da tarde. Dentre os participantes, três eram funcionários há menos de sete anos e oito há mais de vinte anos, sete tinham formação no nível superior (cinco em ciências exatas) e quatro no nível médio. Dentre eles, havia apenas uma mulher. Para identificá-los fez-se uso de nomes fictícios. A análise dos dados empíricos e dos materiais discursivos foi realizada a partir dos conteúdos, sendo objeto de discussões em reuniões no coletivo de pesquisadores profissionais. Realizou-se um Encontro de restituição aos SE dos materiais de análise produzidos, com espaço para discussão crítica e validação do relatório que foi apresentado à direção e gerência da fábrica.

20 A seguir, são apresentados os resultados da pesquisa, cuja discussão em parte é sustentada em extratos de diálogos entre os supervisores que tiveram o papel de coinvestigação e profissionais de pesquisa presentes nos EsT.

\section{Resultados e discussão}

Uma importante diferença observada entre os SE e os antigos chefes de setor foi a de que, do ponto de vista do contrato jurídico de trabalho, deixaram de ser horistas (trabalho em turnos rotativos) e passaram a ser mensalistas (trabalho das 8 às 17h, de segunda à sexta), o que lhes impedia estar fisicamente presentes junto a todas as equipes de operadores de produção. Com o arranjo organizacional recém-introduzido, eles foram convocados a colocar em ação uma proposta de gerenciamento que se pretendia orientada ao desenvolvimento da autonomia $\mathrm{e}$ à delegação de responsabilidades (PR). A eles passaram a ser designadas novas responsabilidades, seja a missão de formação e desenvolvimento de competências dos operadores, seja a mobilização da disposição desses para assumirem tarefas que antes eram dos chefes de setor e líderes de equipes (cargos que tinham sido extintos). Dentre elas estão : controle de presença e distribuição de uniforme, controle de qualidade e quantidade de produtos e disponibilidade de materiais, assim como definição de férias. Isso para que os SE pudessem se concentrar em atividades que a direção classificava "de médio prazo", como preparação de investimentos, proposição de melhorias no processo produtivo e na organização do trabalho, aperfeiçoamento dos procedimentos, acompanhamento e desenvolvimento das competências dos operadores, assistência, orientação e motivação das equipes de trabalho, assim como manutenção da comunicação entre a operação e a direção. De outro lado, esperava-se que eles se envolvessem mais fortemente no gerenciamento da produção, fazendo uso do sistema informatizado de informações industriais.

\subsection{Um trabalho de regulação}

22 Passando a estar posicionados hierarquicamente mais próximos da direção geral, e confirmando a tendência apontada na literatura, as novas tarefas dos SE passaram a ser mais destinadas à coordenação e formação das equipes de operadores. Assim, às variabilidades relacionadas à produção - como as variações na matéria prima, desgastes 
de máquinas e mudanças de prioridades no planejamento da produção - somaram-se as relacionadas às condições de disponibilidade (envolvendo o estado de saúde), capacitação, orientação e formação da vontade dos operadores para as efetuarem. Isso em um quadro de maior exigência de participação dos mesmos no processo produtivo e na gestão da produção. Passando a ser os responsáveis finais pelo planejamento, organização e gerenciamento das operações dos setores de produção (que deveria se dar especialmente pelo resultado de uma eficiente "gestão de pessoas"), os SE faziam tentativas, mesmo que quase sempre insuficientes, de acomodar as múltiplas exigências que se apresentam nas situações concretas de trabalho.

1.023 : Flávio - Você tem que ver que você não lida só com máquinas, tem que lidar com pessoas (...). Esse é o problema : a máquina já tá preconizada. Eu tenho disponibilidade. Esta máquina, neste mês ela vai ficar um tempo parada. Pode ser agora, pode ser depois. Agora, a pessoa é uma incógnita, a qualquer momento... Com o jurídico, eu tive um comunicado que um rapaz foi lá pegar um material no chão e deu um mau jeito na coluna. Aí, estava previsto isso aí ? Não estava previsto. $\mathrm{O}$ cara deu um mau jeito na coluna.

\section{(...)}

1.034 : Diego - (...) Como a gente trata numa situação dessas ? Na verdade, são coisas que nós temos que contar. E aí a gente vai ter que exigir em algum momento um esforço a mais de outras pessoas do grupo para poder suprir isso. (...) Então, menos cinco pessoas e a fábrica tem que estar limpa do mesmo jeito porque tem que atender. Então as pessoas tiveram que ser sobrecarregadas. Só que você sobrecarrega num momento, mas noutro momento você também vai ser penalizado porque você vai estar sem as pessoas da equipe porque elas têm que descansar. (...) E aí são essas variáveis que a gente tem que ter jogo de cintura e habilidade para poder contornar.

Diante de acontecimentos fortuitos, precisavam cotidianamente realizar improvisações e recomposições das tarefas nas equipes para que o trabalho fosse efetivamente realizado. Aponta-se, assim, para um importante componente do trabalho dos SE : a parte ativa que necessariamente tinham que assumir nas regulações (Faverge, 1966) dos eventos que desestabilizavam a organização prescrita do trabalho de produção. Essas regulações ocorriam em meio a múltiplas fontes de prescrição e exigências, seja da direção em termos de limpeza da fábrica e entrega da produção; seja dos operadores que, após uma sobre demanda, apresentavam expectativa de compensação pelo sobreesforço. Como em muitas ocasiões, essas múltiplas exigências revelaram-se contraditórias entre si, exigindo um trabalho de auto-organização (Rogard \& Béguin, 1997). Realizadas no curso de múltiplas variações da demanda e das condições de atividade, as regulações realizadas pelos SE remetiam a um complexo jogo de relações (psico)sociais que se desdobravam em uma renegociação da organização do trabalho, envolvendo as equipes de operadores sob sua responsabilidade, mas também a direção, a gerência, a administração e os serviços de apoio.

2.111 : Renato - (...) A gente tem muita variabilidade e acaba não respeitando o que é prescrito. Será que não está, por deixar de respeitar o que é prescrito, algumas vezes, acaba se tornando variabilidade. Eu acho que a gente não conseguiu 
encontrar essa harmonia entre... (...) “Ah, vem cá... Tem uma reunião que vai ter agora, daqui a quinze minutos e você tem que participar". Ontem eu fui chamado, todos nós fomos chamados a participar de um módulo da formação de qualidade que não estava na nossa agenda. "Ó, o SE tem que estar aqui para o pessoal apresentar...".

2.112 : Flávio - Porém pra gente não teve essa antecipação não aconteceu.

2.113 : Benício - Na verdade, acaba que a gente se adapta tanto, que as pessoas acham já normal que a gente absorva aquela carga. Por quê ? Porque no final a gente consegue fazer. Você se adapta tanto, você se desdobra tanto, que no final as pessoas não tratam com a prévia que deveriam, não se antecipam da maneira que deveriam para a gente se organizar porque a gente acaba fazendo.

Benício, ao comentar o atropelamento da agenda dos SE pela direção e serviços de apoio mencionado por Renato, expressa os custos, a carga adicional de trabalho que eles acabavam assumindo em nome de "se adaptar", de fazer regulações imprescindíveis ao bom andamento do trabalho. Como já assinalava Faverge (1966), as consequências das regulações apresentam-se de modo difuso, mas são acompanhadas de dificuldades e constrangimentos, comportando custos subjetivos. Custos esses que tendem a ser invisibilizados, frente à aceitação de que, impedindo a oficina de se desviar, seriam naturalmente necessárias, e mais : sinônimo de competência. No caso dos SE, esses custos incluíam se mobilizar para ter eficácia em seu trabalho, a despeito de prescrições pouco realistas.

\subsection{Entre as prescrições e a eficácia do seu trabalho}

Curiosamente, havia na empresa uma significativa malha de procedimentos, regras e normas de orientação para o trabalho dos SE. Segundo alguns gerentes da fábrica entrevistados, em função de queixas de falta de tempo por parte dos SE, a direção realizara uma "análise de carga" do trabalho deles. Foi então identificado que, para atender a todas as demandas do "posto", os SE deveriam trabalhar 13 horas por dia, isto é, 5 horas a mais do que o previsto no contrato de trabalho. Assim, a partir do reconhecimento da dificuldade de conciliação de demandas relativas ao trabalho dos $\mathrm{SE}$, foi construída uma agenda que se propunha servir de referência para a "gestão do tempo" de trabalho que os SE deveriam realizar. Essa foi definida por hora, dia e semana, incluindo tempos de preparação e levantamento de informações para cada uma das rotinas, tempo para leitura de e-mail, hora de almoço, preparação e reuniões. Interessante notar que por essa agenda, por mês, os SE contavam com 17,5 horas designadas como "livres", as quais eram indicadas como disponíveis para o "gerenciamento dos imprevistos".

Os SE eram convocados em suas atividades a deliberar entre correr o risco de eficácia no trabalho ou contrariar as prescrições oficiais de organização do tempo. Dentre elas, permitir ser acionado em casa para resolver alguns problemas de trabalho, ou mesmo sentir necessidade de ligar para a empresa para "ver como andam as coisas".

4.370 : Júlio - Eu sou um cara que liga no final de semana, sempre. Ligo duas vezes. 
4.371 : Pesquisador 1 - Você liga pra cá...

4.372 : Júlio - Ligo. Pra ver como está. Não é questão de... ver como é que eles estão trabalhando, né. Por que... (...). Sempre fiz isso no primeiro setor, funcionou bem. Não é cobrando. (...) Eu não espero eles me ligarem. Eles só me ligam quando tem um problema grave. Sim. Aí eu preciso saber por que vai chegar segunda-feira, a gente está calçado. (...) Por que o nosso gerente cobra quando a gente chega na segunda-feira.

Muitas vezes os SE optavam por trabalhar fora do expediente, apesar do risco que reconheciam correr de passar a impressão estar sendo desorganizados, assim como de contrariar a orientação oficial da empresa relativa à chamada qualidade de vida no trabalho. Outras vezes retrabalhavam a prescrição da rotina, de forma a dar tratamento ao que consideravam prioritário, escolhas essas que sempre comportavam riscos.

3.284 : "Hoje eu desabafei com esse cara [apontando para outro SE] : hoje eu vou bicar 30 minutos da rotina do gerenciamento. Porque eu tinha que conversar com um operador... Mas eu fui preocupado".

3.285 : Otávio : Não pode.

3.286 : Rodrigo : Não pode. Eu quebrei todas as regras. (...)

3.287 : Rodrigo : Mas se deixar pra depois, você perde a mão. Tem assunto que você tem que esperar esfriar para tratar. Tem assunto que não pode deixar esfriar, tem que tratar quando ele tá quentinho. (...) Eu vim aqui de madrugada. (...)

3.288 : Otávio : É isso aí.

3.289 : Rodrigo : Encostei o carro aí de madrugada. O cara tomou até um susto quando me viu. "Preciso conversar", "vamos lá conversar..." Quando deu mais ou menos umas 7 horas, tinha terminado a conversa. E ele entendeu.

3.290 : Otávio : Isso é sair do quadrado.

3.291 : Rodrigo : Mas não pode, tá ? Tem qualidade de vida, tem que ter um intervalo entre as jornadas... Mas é o que eu estou te falando, é o que não está escrito, é o que o método não te diz. Mas se você não fizer você perde uma situação mais tarde.

Salientamos o caráter construído das situações de trabalho que exigem essas regulações por parte dos SE, assim como as implicações desses modos de organização das atividades em sua vida e saúde, especialmente no que se refere à dimensão temporal (Teiger, 1987). o discurso que prevalece nesse diálogo retrata a tendência de entender essas regulações como algo natural, necessário e inevitável na realização de seu trabalho, "não fosse, na realidade, a expressão da eficácia relativa de um regime inventado para canalizar e amortecer os antagonismos sociais" (Canguilhem, 1966/2010, p. 222). Naturalizar as exigências de regulação no trabalho dos SE implicaria em tomar esses ajustamentos das partes como regras ou normas imanentes, tal como as 
normas de funcionamento de um organismo, e não como o resultado de antagonismos, soluções paralelas e interesses distintos, característico das normas sociais.

Era nessa mesma lógica de não reconhecimento e debate das contradições, antagonismos e diferenças de interesses que se dava o objetivo fixado aos SE no projeto AR de delegar tarefas e de coordenação do trabalho aos operadores,

\subsection{Supervisionar, coordenar, delegar, formar : estratégias, riscos e custos}

Evidenciou-se no trabalho dos SE a exigência de delegação de algumas tarefas aos operadores. Todavia, essa exigência se apresentava enquanto imposição, tanto aos operadores, que, segundo alguns $\mathrm{SE}$, se queixavam de não serem recompensados pela incorporação de novas responsabilidades, quanto aos $\mathrm{SE}$, na medida em que não era deles a autoridade para definir o que seria possível delegar, para quem e quando.

4.331 : Júlio - Então quando você delegar alguma coisa assim, sendo imposta. "Ó, você vai ter que delegar presenteísmo[8]." Ou : "Você vai delegar férias". Eu não acho legal. Acho legal : "Não. Já que o PR tem que delegar, escolha alguma coisa pra vocês delegarem". Sem impor : "Ó, tem que ser isso aqui". Aí fica mais fácil você trabalhar. Esse problema de presenteísmo é um problema. Eu acho um problema. Porque você deixa a equipe solta. O cara fala que... "Não veio por quê ?". "Não, eu já falei com o responsável na equipe que eu ia faltar..." E fica um buraco na equipe... E você fica um pouco sem... com as mãos atadas. E a empresa pede pra você fazer isso : "tem que delegar". Mas depois como é que você vai pegar as rédeas depois? É complicado.

Essa definição, segundo eles, deveria considerar alguns fatores situacionais: a composição da equipe (4.345), as competências disponíveis (4.329), as consequências de possíveis erros (4.349), assim como suas possibilidades de acompanhamento (4.337) e remediação de um possível erro (4.349). Sinalizavam que, apesar da política ser de delegação, eles é que deveriam responder à hierarquia no final pelo resultado do trabalho.

4.431 : Júlio - Não sei. Eu vejo assim : a responsabilidade vai continuar sendo nossa. Então, como é que tem que fazer ? Tem que trabalhar na delegação, treinar mais as pessoas... Porque ninguém vai cobrar o representante direto, vai cobrar a gente...

4.432 : Antunes - Você delega, mas o responsável é você.

4.433 : Renato - Delegar responsabilidades, mas é nossa a responsabilidade. Porque a gente é responsável, continua sendo responsável, vai ter uma pessoa que vai executar...

4.335 : Júlio - Você perde o domínio, é.

4.336 : Antunes - É. Um atraso que foi acordado com o cara que está fazendo o presenteísmo... 
4.337 : Júlio - Aí você tem muito mais trabalho porque você tem que ficar atrás do do do delegado, né, que fez isso. "E aí, o que aconteceu no dia tal ?" Pô, mas o objetivo não é isso.

Reconheciam que a posição hierárquica dos operadores que recebiam essas delegações (ora denominados "delegados") não lhes daria condição de realizar o trabalho de integração entre as múltiplas exigências que, não obstante, se apresentava como condição para a coordenação do trabalho. Sim, pois não estariam autorizados a negociar com as diversas fontes de proveniência dessas exigências, as quais incluíam instâncias gerenciais e os serviços de apoio.

4.319 : Renato - Isso volta normalmente quando a gente... quando a pessoa tem. Normalmente quando é uma coisa que a própria pessoa... só depende daquela pessoa, ele faz. Agora se ele precisa da ajuda de...

4.320 : Otávio - De terceiros.

4.321 : Renato - De terceiros... de manutenção. (...) Ele precisa de uma ajuda de outro setor, ele vai esbarrar numa dificuldade. E é quando ele para porque senão ele vai passar o dia tentando fazer aquilo e ele não vai fazer a produção que ele tem que fazer. (...)

4.356 : Pesquisador 1 - Agora, foi colocado aqui, o Renato falou de que também tem o o... Quando depende dele, pode ser que ele faça, quando depende exclusivamente dele. Mas quando ele precisa de outra pessoa... É como se essa delegação não fosse reconhecida por outros além do próprio chefe, além de vocês ? (...) Seria isso um dos limites?

4.357 : Renato - Eu acho que sim. É... Às vezes... é é... pelo menos é o que eu percebo é... a pessoa tem a tendência de estar diminuindo aquela necessidade porque o operador foi lá pedir..

4.358 : Pesquisador 1 - Foi o operador, não foi o chefe.

4.359 : Renato - É. E aí... “Será que ele priorizou direito ?”. Será que quando o operador vai lá pedir... “Será que... é realmente a máquina prioritária ?”. Apesar de existirem regras de decisão para isso... Eu vejo... é eu sentindo dificuldade com relação a essa ajuda.

Esse mesmo tema, quando trazido em um diálogo sobre a formação dos "operadores delegados", remete a uma discussão sobre a dobra da carga de trabalho decorrente de ter que formar o operador para que seja possível delegar as tarefas e, ao mesmo tempo, responsabilizar-se pelo resultado.

4.505 : Júlio - Mas tem que ter um acompanhamento inicial. Você vai perder tempo com isso, ...

4.506 : Renato - E ter, e ter um coeficiente de cagaço, né ?

$4.507:[$ risos] 
4.508 : Renato - Um coeficiente, “pera aí, vai errar, mas vai dar tempo de eu corrigir...”. Se eu tiver que acertar alguma coisa... é a análise que tem que fazer, pô. Sem deixar essa margem. suporte nas orientações do sistema de gerenciamento da empresa. Renato sugere que essas estratégias implicavam muitas vezes em uma mobilização de si, que em consonância com o conceito ergológico de corpo-si (Schwartz, 2010) implicava em uma operação fisiológica ("um coeficiente de cagaço") para lidar com o medo produzido pelo risco que corria ao delegar tarefas, pelas quais teria que responder ao final, mesmo sabendo da fragilidade das condições para o operador assumir tal responsabilidade. Indicava fazerem uso de uma margem de segurança para verificar e corrigir possíveis problemas em relação ao resultado final da tarefa delegada, assumindo, também nesse caso, os riscos de forma individualizada e secreta.

Ressalta-se o chamado de adesão dos SE às deliberações oficiais, que muitas vezes subestimavam os problemas relacionados, não apenas à dimensão de eficácia do trabalho, mas principalmente à dimensão ética, dos valores em jogo nas relações psicossociais. No caso das delegações, é importante ressaltar que os operadores não tinham qualquer ganho financeiro para assumir essas novas responsabilidades, apenas a sinalização de que serviriam como aprendizado, experiência a ser considerada em caso de possibilidade de progressão na carreira. Ocorria que muitos deles não estavam convencidos de que valia a pena, restando aos SE a tarefa de convencê-los a assumir essas responsabilidades, na medida em que a imposição já não cabia mais no discurso oficial do gerenciamento dito participativo.

Cada vez mais o trabalho dos SE se apresentava como se dando entre a consideração da realidade das situações concretas de trabalho e o tratamento das dificuldades que lá se apresentavam junto à direção e pares. Entre a diversidade de elementos provenientes das situações concretas a se considerar e a coerência dela com as determinações da hierarquia superior - normalmente em forma de objetivos fixados de forma distanciada da realidade concreta da produção - há um esforço efetuado pelos SE de construção de sentido e coerência na confrontação constante de suas interpretações das situações com as de tantas outras envolvidas no trabalho. Sobre a questão, os ergonomistas Carballeda e Garrigou (2001) trazem como hipótese as implicações disso na saúde dos profissionais de supervisão.

\subsection{Gerenciar "com as mãos atadas"}

Coordenar o trabalho coletivo implica na exigência de estabelecimento de alianças e negociação de compromissos com os diversos atores organizacionais. Mas, como gerenciar (palavra cuja origem etimológica envolve manejar) de mãos atadas ? Em um diálogo sobre o questionamento feito pela gerência quando um SE liberou os operadores para descansar em determinados dias para compensar por um esforço extra, um SE afirma :

2.119 : Júlio - Autonomia é você meter o código e não ser questionado 
2.120 : Jorge - Mas isso é o que nós não temos, já que vem a pergunta : "Por que você aplicou este código assim ?".

2.121 : Amauri - Agora... Acho que isso reflete no seu trabalho. Eu acho que a gente tem que ser cobrado pelo teu resultado. Como você faz o resultado - é claro, sempre respeitando as normas, as regras - eu acho que você tinha que ter essa autonomia para fazer da forma como... Se a empresa te contratou, eu acho que ela tem que te deixar realizar o trabalho. Né ? Porque essa questão de deixar o cara abonar a ausência do cara é o teu tempero, é a forma como você vai fazer a gestão da tua equipe. Se isso é tirado da gente...

2.122 : Benício - Você fica com as mãos...

(...)

2.127 : Flávio - Eu digo pra você o seguinte... São pequenas coisas... Tinha uma insatisfação muito grande num departamento por que... tinha um departamento Não aqui nessa fábrica, mas numa outra - em que todos os outros departamentos, o cara poderia, se tivesse tranquilo na máquina, cinco minutos antes ele subia, tomava o banho dele e aí passava o cartão. Coisa pouca ! Você tá entendendo ? Você vai trocar uma roupa : "pô, eu vou numa reunião que vai ser às 16 horas". Tu para cinco minutos antes, toma o teu banho, vai na reunião. (...) Então, quer dizer, funcionário ficava... os outros, "pô, cara você não pode ? Todo mundo tomou banho..." o cara, "é, mas eu não posso". Entendeu ? Uma coisinha boba, que você ficava amarrado e... Cara aí tu dá essa liberdade... Pô... entendeu ? Já faz a diferença.

2.128 : Amauri - A gente toma certas decisões, que a gente tá ali no dia a dia, convivendo com as pessoas (...). E quem vem de fora e não participa, não tá ali no convívio, é... questiona e e muitas vezes não entende a a decisão que foi tomada.

2.129 : Pesquisador 2 - Não percebe talvez como é que esses cinco minutos podem fazer diferença. Pra você que está de fora... “Oh... que isso ?".

2.130 : Amauri - Friamente, quando você olha de fora, você acha : "pô, o cara tá liberando o cara cinco minutos antes, virou bagunça isso ?". Mas quando você entra no contexto da coisa, você vê que...

Os SE tinham que considerar, nas microescolhas de suas atividades, que eles poderiam ser cobrados e teriam que justificar suas decisões. "Coisinha boba", dentre as tantas outras decididas no decorrer de um período de trabalho, pode ser esquecida, colocando-o em risco caso tivesse que se justificar. Explicações que deveriam ser dadas a um interlocutor distanciado das situações singulares em que essas microdecisões foram tomadas. Um interlocutor sempre sob pressões diversas quanto a resultados em termos de valores mercadológicos (competitividade), o que poderia levá-lo a ter dificuldade para compreender as justificativas ou as priorizar em sua avaliação do trabalho.

Ao tratar as dificuldades que se apresentavam no decurso do trabalho junto à direção $\mathrm{e}$ aos pares, os SE se deparavam com um lugar onde as dificuldades podiam ser expressas de forma menos explícita e mais difusa por um conjunto de discursos que remontam a 
uma previsibilidade do processo de trabalho. Discursos estes sustentados por uma ideologia que define como bom profissional aquele que não traz os problemas cotidianos (tidos como menores) para serem discutidos, pois que deve saber tratá-los ali onde ocorreram, pois afinal este seria um bom gestor, o que lhe exigiria, nas situações concretas de seu trabalho, construir parcerias.

\subsection{Construção de canais de parceria}

Schwartz (2004) adverte que não se pode "governar, gerir o trabalho como se geríssemos um deserto de gestões. Gerir o trabalho dos outros é sempre aprender a gerir as gestões" (Schwartz, 2005, p. 12, grifos do autor). Entretanto, pensando na formação social brasileira, com sua tradição escravista, que ao longo do tempo, em cada história local e conjuntura específica, foi agregando elementos do coronelismo, militarismo e positivismo, onde os chefes, dirigentes, gerentes, administradores, foram formatados (e cobrados) para saber das coisas e preservar sua posição neste plano, supõe-se que operar um gerenciamento orientado pelo ponto de vista da atividade (que permite considerar que cada um que trabalha, em alguma medida, faz a gestão) não seja algo muito comum. Promover um gerenciamento do trabalho reconhecendo-o não apenas como mera aplicação de normas e regras ou execução de tarefas, mas considerando o que se mobiliza do sujeito para sua realização frente às situações reais que são dinâmicas, instáveis e imprevisíveis implicaria em abordar cada situação de trabalho em sua concretude, globalidade e complexidade, considerando suas diferentes problemáticas. Claro, considerando o que foi dito, não se trata de algo fácil, especialmente quando o discurso oficial do gerenciamento opera a partir de outra lógica. Paradoxalmente, tampouco ignorar a presença da potência de gerir de quem trabalha é algo facilmente contornável, haja vista a proximidade desses profissionais de supervisão com o "chão de fábrica" e a sua convivência com a complexidade das situações que lá se desenrolam.

41 Apesar de raras, algumas passagens nos diálogos que circularam nos EsT sugerem um potencial de desenvolvimento do modo de gerenciar que leva em consideração as microgestões realizadas pelos operadores nas situações concretas de trabalho. $O$ trecho de fala abaixo denota a concordância de um SE com os princípios dessa forma de gerenciar :

5.597 : Renato - E o trabalho real. Eu acho que tem que saber, a gente precisa saber o trabalho real. Quando a gente faz o manual PR, quando a gente coloca de regras de vida, quando a gente coloca é é uma porção de formulário para o pessoal preencher... No papel fica tudo muito bonito, fica tudo legal. Mas... é importante a gente ver se é o que está prescrito. É importante a gente estar lá e saber realmente que trabalho real ele vai ter. Ele vai conseguir fazer aquilo ? É necessário fazer aquilo? Aquilo ajuda? Aquilo tá atrapalhando o operador ? E a gente acaba colocando ali o que pra aquele momento o que a gente viu que é bom, mas para o contexto de fábrica, no momento que ele está, na sua marcha corrente, vai atrapalhar toda a rotina do operador (...). Tem coisas que está lá prescrito, mas a gente sabe que a atividade vai ser uma coisa muito difícil de ser realizada, principalmente porque talvez não seja o melhor momento. 
Algumas práticas relatadas pelos SE também apontaram para a impossibilidade de se adotar um modo de gerenciar baseado apenas na mera aplicação, transmissão e tradução das prescrições e políticas da empresa. Revelaram saber que seu trabalho implica, muitas vezes, "favorecer uma determinada situação" (2.127), como, por exemplo, liberar os trabalhadores cinco minutos antes do horário oficial. Segundo alguns SE, seria essa uma estratégia possível, considerando a necessidade de estabelecer e manter uma parceria com os operadores para a realização do trabalho.

2.133 : Benício - E se você é muito muito caxias, no final o cara inventa $n$ motivos por não ter feito a produção, que depois você mesmo fica com o seu resultado prejudicado. É... pô... Às vezes ele tira cinco minutos antes do almoço dele, mas para sair cinco minutos antes. Então, é...

2.134 : Flávio - A gente tá falando de mixaria, tá ? Não tá falando em termos de... não vou dar cinco... "meu amigo, vou te dar de presente cinco dias". (...)

2.135 : Renato - Não é mercenário.

2.136 : Flávio - E sim valorizar o esforço daquela pessoa. E lembrando do seguinte : você não tem como enxertar um dinheiro na sua conta, não tem como te diferenciar, não tem nada disso. Então, um recurso que você tem é, é favorecer uma determinada situação.

Realizar "ajustes para dar conta do trabalho" (2.072 a 2.089) envolvia efetuar escolhas nos debates de normas, nos quais valores, para além dos econômicos, poderiam estar sendo convocados. Parece que era necessária aos SE uma interpretação das situações de trabalho do seu próprio ponto de vista, e não apenas o das orientações gerenciais na construção de um modo de tratar as pessoas, de falar e de fazer socialmente posicionados. Segundo Mispelblom-Beyer (2010), este modo de fazer se expressa tanto no dito quanto no não dito, nas palavras e também nos atos, nas práticas de trabalho, muitas vezes em acordo, mas também em contradição com as regulamentações.

2.159 : Flávio - Eu vou falar o "discordando ou não". Certo ? Teve um comunicado que chegou tardiamente, que foi o seguinte : "a partir de amanhã, quem tem um plano [de saúde] enfermaria, não pode mudar para o plano quarto".

2.164 : Flávio - Pô, eu, eu ! Como é que eu vou passar para o cara que a partir de ontem... Você tá entendendo ? (...)

2.172 : Pesquisador 1 - Tem que passar uma sinceridade, uma verdade para as pessoas.

2.173 : Flávio - É isso aí... Transparência. Se você não faz isso, não adianta que o cara não vai ser aquele... É o que eu falo, eu não quero ser melhor que ninguém, eu não quero que você chegue lá fora, "pô, eu quero ser seu amigo", não. Mas aqui dentro eu tenho que te respeitar, você me respeitar e ser profissional. (...) Então eu procuro não ter surpresas. (...) 
2.174 : Renato - É complicado e perigoso ao mesmo tempo. Porque dependendo da nossa reação, a gente pode gerar reações também nas pessoas. tipo que se apresentava deflagrava um debate de normas, onde a ordem de prioridade dos valores convocados nas microdecisões de suas atividades era sempre provisória. Nesses debates, tanto o valor respeito aos funcionários, quanto o valor responsabilidade com a empresa apresentavam um peso significativo, o que faz com que, apesar de se reconhecer a dimensão social nos debates de normas das atividades dos supervisores, dificilmente se pode pensar em uma liberação da exigência de buscar apoio no discurso oficial do gerenciamento, na medida em que o sistema de avaliação formal de seu trabalho se sustentava nos pressupostos desse discurso.

\subsection{Tornar-se "gestor", aderir ao discurso oficial}

Em autoconfrontação a um trecho de conversa da pesquisadora 1 com um SE - a partir da fala "tudo cai na mão do SE", referindo-se às exigências de diversas fontes na empresa, incluindo as das prescrições do gerenciamento em relação ao tempo e aos procedimentos indicados para a formação, delegação, acompanhamento da rotina, dentre outras - os supervisores reconheceram que o tempo não era suficiente, embora tendessem a reproduzir o discurso oficial do gerenciamento de atribuição de (in)competência aos que conseguem ou não fazer a gestão do tempo e das variabilidades.

2.096 : Flávio - O que acontece... O que a gente vê é que o processo ele não... Embora você tenha as regras, você tem tudo, mas... não é engessado o processo. (...)

2.097 : Amauri - Eu acho que se a gente seguisse o prescrito, o que é preconizado para a função do SE, a questão do tempo não seria um problema. Só que a gente, a todo momento, é envolvido na questão da variabilidade, que compromete o que está prescrito e acaba o tempo, a gente não conseguindo realmente fazer o que está preconizado. Então é... acho que o segredo está em fazer a gestão da variabilidade (...) Acho que o segredo tá nisso.

Mas como "saber lidar" / "fazer a gestão" ? Que custos comportam este "lidar" / "gerir"?

2.098 : Pesquisador 1 - E como se desenvolve essa capacidade ?

2.100 : Amauri - Acho que a experiência.

2.101 : Benício - O ambiente industrial é muito complexo.

2.102 : Otávio - É muito dinâmico. E não sei se a gente... Você falou aí num ponto... Porque o variável é algo de novo que aparece, não é isso ? (...) Foi o que o Flávio, o exemplo do Flávio. Uma hora que dançou. Ele estava preparado para dançar nessa uma hora?

2.103 : Amauri - Nem sempre ele está preparado, mas... 
2.104 : Otávio - Então... [inaudível] Uma hora é uma hora, uma hora tu não volta atrás não. Sabe como ele compensa essa uma hora dele ? Deixando de fazer alguma coisa ou ficando até às $18 \mathrm{~h}$. Ponto.

[Silêncio] múltiplas exigências nas tarefas dos SE seria solucionada com a aquisição dessa competência? Esse enunciado exemplifica outros tantos produzidos nos diálogos dos SE nos EsT: uma tendência a evoluir sem confrontos e apagar as contradições e os elementos de tensão no real do trabalho. Durante os contatos da pesquisadora 1 no campo $\left[{ }^{\circ}\right]$, pôde-se perceber uma tendência de enquadre das falas proferidas em público em relação às expressões em situações privadas. As primeiras tendem a se aproximar de uma reprodução do discurso oficial do gerenciamento, não apenas em relação ao trabalho do operador, mas em relação ao seu próprio. No plano linguageiro, França (2005) indica ser essa uma via possível no diálogo realizado quando nele predominam forças centrípetas. Essa via produz um efeito de aparente uniformidade de pensamento, convergente para um único ponto de vista, um sobredestinatário comum. Nesse caso, o que o gerenciamento da direção indicava como diretrizes e objetivos estratégicos da empresa, os quais eram sustentados por um conjunto de normas, balizadas em um referencial científico-positivista e uma ideologia gerencialista, que convocam prioritariamente valores mercantis de eficácia, rentabilidade, objetividade, utilidade, funcionalidade e previsibilidade. Ocorrendo em uma situação pública, essa foi a principal via adotada nos diálogos nos EsT. De modo geral, as produções linguageiras se orientavam para indicar que o modo de organização do trabalho não deveria ser questionado, apenas "gerido" (no caso, entendido como ajustado, adaptado). Se algo deveria mudar, eram os trabalhadores. Se havia disfuncionamentos, eram eles, com suas incompetências e/ou interesses particulares que as promovem.

Percebe-se assim no discurso dos SE indícios do que Dejours e Jayet (1994) chamaram de psicologia espontânea do executivo, a qual por meio de um olhar pejorativo sobre os operadores (expresso no enunciado 3.277: "A batata podre não vai, não adianta...") ocultaria o desafio dos mesmos em sustentar o domínio imperfeito do processo de trabalho e da distância entre a organização prescrita e a organização real. Em alguns momentos nos diálogos notam-se os SE atribuindo aos operadores falta de empenho, falta de seriedade ("O problemático para mim é aquele que tá lá, não entrega o resultado, não faz e não te explica porque que está fazendo" - 3.239), falta de responsabilidade ("Ele tem todas as justificativas. Primeiro : 'eu não tenho formação...' Depois : ‘eu não tinha a informação’ [...] Ele fica dando desculpa [...]” - E3.218) ou falta de competência, o que pode distanciar a possibilidade de construção de fundamentos para uma negociação coletiva da organização real do trabalho.

Por mais que se sustente a não submissão total das pessoas que trabalham aos imperativos das normas antecedentes fundadas em valores monetários, há que se 
reconhecer seu grande peso nas atividades de trabalho dos SE. Foi por eles apontado como "fato" que a competitividade está relacionada à sobrevivência da empresa (5.567-5.568), levando à necessidade de "se calçar", de "ter essas armas nas mãos" para quando vierem as cobranças em relação às metas estabelecidas, campo no qual a manutenção do emprego e o desenvolvimento de sua carreira estão em jogo.

51 Assim, os materiais produzidos nos diálogos sinalizam para a exigência trazida por essa reconfiguração de seu trabalho no sentido de adesão ao discurso oficial da empresa. Mais do que a outros trabalhadores que são cobrados (todavia mais indiretamente) pelas decisões de conciliação de diversas dimensões (muitas vezes incompatíveis) nas situações concretas de trabalho, aos SE é imputada a responsabilidade final pelas consequências das decisões tomadas no chão de fábrica. Essa imputação é feita desconsiderando-se que o processo de produção só pode efetivar-se a contento na medida em que se viabilize a gestão do trabalho que é sempre social e coletivo. Colaborar para essa estruturação coletiva, que é sempre fluida e frágil, considerar a situação de trabalho em sua concretude, globalidade e complexidade, admitir as infidelidades do meio, assim como a não disposição de todos os meios e ferramentas de antecipação do trabalho, parece ser um desafio difícil de ser enfrentado, especialmente em um trabalho em que, apesar das múltiplas interações, se dá de forma tão solitária. Tão difícil que na maioria das vezes se prefira a via mais óbvia : reproduzir o discurso e as orientações do gerenciamento, operando com base na autoridade hierárquica, nas prescrições e na crença da possibilidade de total antecipação do trabalho.

\section{Considerações finais}

Dentre os elementos do processo de trabalho, a atividade (trabalho vivo, concreto) é aquela que dá vida ao mesmo, na sinergia com os outros elementos que o compõe. Não obstante, parece persistir a adoção de modos e modelos de gerenciamento baseados mais no trabalho abstrato, objetivado de forma estreita à prescrição de tarefas ; mais no controle de indicadores e resultados e menos no trabalho concreto, nos processos e nas relações de trabalho. Soma-se a isto a manutenção da visão dos trabalhadores (incluindo os gerentes) como meros recursos, o que contribui para um distanciamento da realidade vivida nas situações de trabalho, explicitada, tanto no discurso oficial do gerenciamento, quanto na literatura da área, muitas vezes com a expressão fator humano.

53 A despeito desse quadro, buscou-se nessa pesquisa privilegiar uma dinâmica relacional entre os diversos fatores presentes na complexidade das situações de trabalho, na qual os SE não seriam vistos como apenas passivos pontos de impacto, mas também como aqueles que escrevem a sua história. Assim, partindo do pressuposto ergológico de que trabalhar é gerir (Schwartz, 2004), buscou-se analisar em que medida, intensidade e forma os profissionais que gerenciam fazem cotidianamente uma gestão (não apenas do outro, mas de si próprio) na qual valores de vida e de saúde estivessem também convocados.

Os resultados mostraram que essa gestão, que apesar de remeter a negociações de eficácia, não é reconhecida em seus custos, na tentativa cotidiana de fazer conciliar exigências, muitas vezes contraditórias, provenientes de diversas fontes de prescrição e de objetivos a alcançar. Realizado na fronteira entre as prescrições do gerenciamento, políticas e diretrizes da empresa e a realidade da produção, o trabalho dos SE revelou 
envolver a busca de pontos de convergência, de regularidade, de constância, não como as que se apresentam nos relatórios gerenciais, mas com as que se configuram nos fatos e nas situações concretas de trabalho. Os diálogos produzidos nos EsT evidenciam que as atividades dos SE se configuravam em meio a informações imprecisas, muitas conflitantes e discordantes entre si, provenientes de fontes esparsas na empresa. Ao mesmo tempo, essas atividades ocorriam em relação dinâmica, com interferências diversas e em cooperação com numerosos atores, assim como em referência a várias fontes de prescrições e expectativas. Conforme esperado, regulações de orientação funcional faziam parte das atividades de trabalho dos SE, tendo eles uma participação importante na organização real do trabalho. Assim, no lugar de previsibilidade, planejamento e constância, no cotidiano de seu trabalho revelaram ser preciso lidar com imprevistos, variabilidades, diferentes expectativas e demandas, contradições entre normas e regras. Mas as condições de intercompreensão nunca se encontravam inteira e perfeitamente reunidas.

O enquadramento do trabalho dos SE na categoria de um trabalho gerencial, traz uma pressão pela adoção de um discurso oficial, da empresa e do gerenciamento que, ao contrário da linguagem subjetiva da vivência, pressupõe o tratamento de fatos e dados objetivos e quantitativos, possibilidade de antecipação dos eventos e previsibilidade dos resultados. Entretanto, suas atividades de trabalho, além de serem orientadas por normas e objetivos predeterminados pelo sistema de gerenciamento, especialmente em favor do desempenho econômico da empresa, apontaram também para uma capacidade normativa desses profissionais (de produzir novas normas, mesmo que não totalmente formuladas, acabadas e precisas), onde valores relativos à vida em conjunto e à saúde eram também convocados. Muitos reconhecem o mundo do trabalho em uma sociedade capitalista como se limitando ao reino pleno dos interesses privados, onde imperaria a exploração e a violência (inclusive simbólica) como forma de regulação econômica, e o trabalho como uma atividade puramente técnica. Com a pesquisa realizada, foi possível identificar, por meio da coanálise de situações concretas de trabalho, das comunicações e das relações intersubjetivas nelas estabelecidas, a existência de dimensões sociais nas atividades de supervisão do trabalho, cujas dinâmicas extrapolam a exploração mecânica.

Identificam-se limites na experimentação que foi feita deste dispositivo de pesquisaintervenção. Um em especial está relacionado ao contexto político em que se pretendeu descrever e analisar a experiência dos SE, reunindo profissionais que têm responsabilidades idênticas, que ocupam o mesmo cargo, mas que na verdade não possuem um trabalho prioritariamente coletivo. Ao contrário, em parte têm os resultados de seu trabalho tomados pela hierarquia como objeto de comparação, mesmo que em uma análise que privilegia os desempenhos e não uma avaliação do trabalho enquanto atividade. Reconhecem-se, portanto, razões estratégicas para manter secretos certos aspectos da relação dos SE com o próprio trabalho, na medida em que sua revelação poderia fazer perder alguma vantagem na negociação de sua autonomia. Outro limite refere-se à construção social do contrato da pesquisaintervenção, que, pela via de negociação da demanda pela direção da fábrica, foi reconhecido pelos participantes como uma ação vinculada à política de gerenciamento da empresa. 


\section{BIBLIOGRAFIA}

Athayde, M., Muniz, H., França, M. \& Figueiredo, M. (2010). A perspectiva da ergologia e o campo da saúde mental e trabalho. In D. Glina \& E. Rocha (Orgs.), Saúde mental e trabalho : da teoria à prática (pp. 229-247). São Paulo : Roca.

Athayde, M., Zambroni-de-Souza, P. \& Brito, J. (2014). Intervenção e pesquisa em psicologia : uma postura ergológica. In P. Bendassolli \& L. Soboll (Orgs.), Métodos de pesquisa e intervenção em psicologia do trabalho : clínicas do trabalho (pp. 129-157). São Paulo : Atlas.

Athayde, M. \& Rezende, M. (2015). Atividade. In P. Bendassolli \& J. Borges-Andrade (Orgs.), Dicionário de psicologia organizacional e do trabalho (pp. 101-108). São Paulo : Casa do Psicólogo.

Bendassolli, P. \& Soboll, L. (Orgs.) (2014). Métodos de pesquisa e intervenção em psicologia do trabalho : clínicas do trabalho. São Paulo : Atlas.

Bellini, S. \& Labit, A. (2005). Des petits chefs aux managers de proximité : L'évolution des rôles de la maîtrise dans l'industrie. Paris : L'Harmattan.

Bouffartigue, P. \& Bouteiller, J. (2004). A l'épreuve du travail des cadres. A propos d'une expérience de recherche. Artigo apresentado no primeiro congresso da Associação Francesa de Sociologia. Villetaneuse, France.

Canguilhem, G. (1947/2001). Meio e normas do homem no trabalho. Pro-posições, 12 (2-3), 35-36.

Canguilhem, G.(1966/2010). O normal e o patológico. Rio de Janeiro : Forense.

Carballeda, G. \& Garrigou, A. (2001). Derrière le “ stress », un travail sous contraintes. In P. Bouffartigue (Ed.), Cadres : la grande rupture (pp. 89-105). Paris : La Découverte.

Christo, C. (2013). Análise da atividade de supervisão do trabalho : um olhar Psico-social para o gerenciamento na indústria. Tese de Doutoramento. Universidade do Estado do Rio de Janeiro, Rio de Janeiro.

Clot, Y. \& Leplat, J. (2005). La méthode clinique en ergonomie et en psychologie du travail. Le Travail Humain, 68, 4, 289-316.

Dejours, C. (1999). A banalização da injustiça social. Rio de Janeiro : FGV.

Dejours, C. \& Jayet, C. (1994). Psicopatologia do trabalho e organização real do trabalho em uma indústria de processo : metodologia aplicada a um caso. In C. Dejours, E. Abouchelli \& C. Jayet (Eds.), Psicodinâmica do trabalho : contribuições da escola dejouriana à análise da relação prazer, sofrimento e trabalho (pp. 67-118). São Paulo : Atlas.

Durrive, L. (2010). Pistas para o ergoformador animar os encontros sobre o trabalho. In Y. Schwartz \& L. Durrive (Orgs.), Trabalho \& Ergologia : conversas sobre a atividade humana (pp. 309-318). Niterói : EDUFF.

Faïta, D. \& Maggi, B. (Eds.) (2007). Un débat em analyse du travail : deux méthodes em synergie dans 1 'étude d'une situation d'enseignement. Toulouse : Octarès.

Faïta, D. \& Duc, M. (1996). Savoir-faire d'encadrement et prescription floue. In J. Girin \& M. Grosjean (Orgs.), La transgression des règles au travail (pp. 51-81). Paris : L'Harmattan.

Falcoz, C. \& Livian, Y. (2006). Que sait-on du travail des managers ? In Y. Livian (Org.), Etre cadre, quel travail ? Organization et Technologie (p.58-84). Paris : Anact. 
Faverge, J.M. (1966). L'analyse du travail en terme de régulation. In J.M. Faverge, M. Olivier, J. Delahaut, P. Stephaneck, P. \& J.C. Falmagne (Orgs.), L'ergonomie des processus industriels (pp. 33-60). Bruxelles : Université Libre de Bruxelles.

Fayol, H. (1916/1968). Administração Industrial e Geral (7. ed.). São Paulo : Atlas.

França, M. (2005). o trabalho de recepcionistas de guichê de hospital público universitário : o ponto de vista teórico-metodológico de uma Comunidade Dialógica de Pesquisa. Laboreal, 2, 1 , 06-17.

Gaulejac, V. (2007). Gestão como doença social : ideologia, poder gerencialista e fragmentação social. Aparecida/SP : Ideias e Letras.

Guérin, F., Laville, A., Daniellou, F., Duraffourg, J. \& Kerguelen, A. (2001). Compreender o trabalho para transformá-lo : a prática da ergonomia. São Paulo : Edgar Blücher.

Lhuilier, D. (2006). Cliniques du Travail. Toulouse : Érès.

Mascia, F. (2007). O trabalho da supervisão : o ponto de vista da ergonomia. In P. Falzon (Ed.), Ergonomia (pp. 609-625). São Paulo : Blücher.

Mispelblom-Beyer, F. (2010). Encadrer, un métier impossible? Paris : Armand Colin.

Mispelblom-Beyer, F. \& Bismuth, D. (2009). Autorité et connaissance dans les dispositifs d'analyse des pratiques d'encadrement. Education permanente, 178, 1, 55-78.

Pinsky, L. \& Theureau, J. (1982). Activité cognitive et action dans le travail : éléments et événements du travail infirmier. Paris : CNAM.

Rocha, D., Daher, M.C. \& Sant'anna, V. (2004). A entrevista em situação de pesquisa acadêmica : reflexões numa perspectiva discursiva. Revista Polifonia. 8, 08, 161-180.

Rogard, V. \& Béguin, P. (1997). L'ergonomie au risqué du travail des cadres. Performances Humaines \& Techniques, 91, 8-10.

Rousseau, D.M. \& Parks, J.M. (1993). The contracts of individuals and organizations. Research in Organizational Behavior, 15, 1-43.

Schwartz, Y. (2004). Trabalho e gestão : níveis, critérios, instâncias. In M. Figueiredo et al (Orgs.), Labirintos do Trabalho (pp. 23-33). Rio de Janeiro : DP\&A.

Schwartz, Y. (2005, julho). Trabalho e saúde : construindo outros modos de gestão. Comunicação apresentada em Mesa redonda no Congresso da ABRASCO. Florianópolis, Brasil.

Schwartz, Y. (2007). Un bref aperçu de l'histoire culturelle du concept d'activité. Revue électronique @ctivités, 4, 2, 122-133.

Schwartz, Y. (2010). A experiência é formadora ? Educação e Realidade, 35, 1, 35-48.

Schwartz, Y. (2011). Manifesto por um ergoengajamento. In P. Bendassolli \& L. Soboll (Orgs.),

Clínicas do trabalho : novas perspectivas para a compreensão do trabalho na atualidade (pp :132-166). São Paulo : Atlas.

Schwartz, Y. \& Durrive, L. (Eds.) (2009). Activité em dialogues : entretiens sur l'activité humaine II. Toulouse : Octarès.

Schwartz, Y. \& Durrive, L. (Eds.) (2010). Trabalho e Ergologia : conversas sobre a atividade humana (2a. ed. ampl.). Niterói : EDUFF.

Teiger, C. (1987). L'organisation temporelle des activités. In C. Lévy-Leboyer \& J. C. Sperandio (Orgs.), Traité de psychologie du travail (p. 659-682). Paris : PUF. 
Trouvé, P. (2009). La contribution des entreprises à la formation de leur encadrement intermédiaire : un investissement sans retour ? Education permanente, 178, 1, 37-53.

\section{NOTAS}

1. No Brasil, essa posição na organização do trabalho pode ser referida por diferentes denominações, como chefe de setor, chefe de equipe, contramestre, supervisão direta, hierarquia intermediária, gerente de primeiro nível, gerente de linha e coordenador. Em língua francesa, usam-se, dentre outros, os termos encadrement de proximité, encadrement de premier niveau, agents de maîtrise, cadres encadrants, contremaîtres e gestionnaires de premier niveau. Já em língua inglesa, é comum o uso dos termos supervisors, first-line managers ou midle management. 2. O levantamento foi realizado em agosto de 2017, orientado para a busca de artigos em todos os idiomas disponíveis, especialmente em bases de dados no campo da Psicologia, Engenharia, Ciências Sociais e Business \& Economics, utilizando-se os descritores WORK e SUPERVISOR na busca por assunto.

3. A pesquisa foi realizada, de setembro de 2012 a janeiro de 2013 e foi realizada com financiamento da CAPES e do CNPq, na forma de bolsa de Doutorado e de Doutorado Sanduich.

4. Além dos autores do artigo, participaram desse coletivo o prof. Dr. Hélder Pordeus Muniz e a então doutoranda Ana Paula Taveira Leite.

5. Conceitos e noções discutidas com os participantes: trabalho prescrito, trabalho real, tarefa, atividade, situação de trabalho, variabilidades da produção, exigências temporais, diversidade e variabilidade das pessoas, análise da atividade, relações com a saúde e segurança, usos de si (por si, pelos outros), competência e gerenciamento ergológico.

6. Foram realizadas cinco reuniões (gravadas em áudio) no coletivo de pesquisadores profissionais com essa finalidade.

7. Desses, dois compareceram aos quatro Encontros e um em três. Dois foram substituídos na função (um por promoção de cargo, outro por demissão) durante a realização dos Encontros e três participaram apenas de um Encontro.

8. O SE se refere ao controle de frequência dos operadores daquela equipe, que deve ser delegado a um de seus membros.

9. Antes mesmo da realização dessa investigação, a pesquisadora 1 realizou frequentes visitas às unidades fabris dessa empresa, tendo variadas oportunidades de conversas com membros da direção, gerência e média gerência.

\section{RESUMOS}

Discutem-se no texto os resultados de uma investigação realizada em uma indústria de fabricação de pneumáticos. Realizado na fronteira entre as prescrições, políticas e diretrizes da empresa e a realidade da produção, o trabalho de supervisão foi o objeto de pesquisa. Teve-se como objetivo identificar as implicações subjetivas e intersubjetivas na realização desse trabalho, a partir das exigências emergentes no processo de reconfiguração das responsabilidades de supervisores de produção. $O$ método baseou-se na autoconfrontação dos sujeitos com suas atividades, a partir de textos produzidos em diálogos sobre o trabalho que circularam ao longo de entrevistas, 
observações e encontros coletivos de discussão sobre o trabalho. Os resultados apontam para uma pressão pela adoção de um discurso oficial, baseado em racionalidade objetivista e utilitarista que se confronta com outra, produzida no curso das situações concretas de trabalho.

Se analizan en el texto los resultados de una investigación realizada en una industria de fabricación de neumáticos. Realizado en la frontera entre las prescripciones, políticas y directrices de la empresa y la realidad de la producción, el trabajo de supervisión fue el objeto de la investigación. Se buscó identificar las implicaciones subjetivas e intersubjetivas en la realización de este trabajo, a partir de las exigencias emergentes en el proceso de reconfiguración de las responsabilidades de los supervisores de producción. El método se basó en la autoconfrontación de los sujetos con sus actividades, a partir de textos producidos en diálogos sobre el trabajo que circularon durante las entrevistas, observaciones y reuniones grupales de discusión sobre el trabajo. Los resultados indican una presión hacia la adopción de un discurso oficial, basado en la racionalidad objetivista y utilitarista que se enfrenta a otra, producida en las situaciones concretas de trabajo.

Le texte décrit les résultats d'une enquête menée dans une industrie de fabrication de pneus. Se situant à la frontière entre les prescriptions, les politiques et directives de l'entreprise et la réalité de la production, le travail de supervision a fait l'objet de la recherche. L'objectif était d'identifier les conséquences subjectives et intersubjectives de ce travail en fonction des exigences émergentes dans le processus de reconfiguration des responsabilités des superviseurs de production. La méthode repose sur l'auto-confrontation des sujets avec leurs activités, à partir de textes produits lors de dialogues sur le travail qui ont circulé au cours des entretiens, des observations et des discussions collectives. Les résultats indiquent l'existence d'une pression pour l'adoption d'un discours officiel, basé sur une rationalité objectiviste et utilitariste, qui se confronte à une autre rationalité produite dans le cours des situations de travail réelles.

The text discusses the results of an investigation carried out in a tire manufacturing industry. The supervisory work was the research object, located at the boundary connecting requirements, policies and company guidelines as well as the production reality. The objective was to identify the subjective and intersubjective implications in the completion of the work from the emerging requirements in the reconfiguration process of the production supervisors' responsibilities. The method was based on the self-confrontation of the subjects with their activities; it was substantiated on texts produced in dialogues about work that circulated during interviews, observations and collective discussion meetings about work. The results indicate a pressure for the adoption of an official speech based on an objectivist and utilitarian rationality that is confronted with another rationality produced in the course of actual work situations.

\section{ÍNDICE}

Palabras claves: trabajo de supervisión, autoconfrontación, clínica del trabajo, ergología

Keywords: supervision work, self-confrontation, work clinic, ergology

Palavras-chave: trabalho de supervisão, autoconfrontação, clínica do trabalho, ergologia

Mots-clés: travail de supervision, auto-confrontation, clinique du travail, ergologie 


\section{AUTORES}

\section{CIRLENE DE SOUZA CHRISTO}

Universidade Federal do Rio de Janeiro Instituto de Psicologia. Av. Pasteur, 250 Urca, Rio de Janeiro, RJ CEP 22290-902, Rio de Janeiro, RJ, Brasil, cirlenechr@gmail.com

\section{MARCELLO SANTOS REZENDE}

Fundação Oswaldo Cruz, Coordenação de Saúde do Trabalhador. Av. Brasil, 4365 - Pavilhão Carlos Augusto da Silva, Sala 114. Manguinhos - Rio de Janeiro, RJ - Brasil. CEP : 21040360 , marcellosantosr@gmail.com

\section{MILTON ATHAYDE}

Universidade do Estado do Rio de Janeiro, Instituto de Psicologia. Rua Sao Francisco Xavier 524, sala 10.009, bloco F, Maracanã, Rio de Janeiro, Brasil, athayde.milton@gmail.com 